\title{
Pulmonary Hemodynamic and Ultrastructural Changes Associated with Group B Streptococcal Toxemia in Adult Sheep and Newborn Lambs
}

\author{
JORGE ROJAS, ${ }^{(27}{ }^{28)}$ LARS E. LARSSON, CARL G. HELLERQVIST, KENNETH L. BRIGHAM, \\ MARY E. GRAY, AND MILDRED T. STAHLMAN \\ Departments of Pediatrics, Biochemistry, Medicine and Pathology, Vanderbilt University School of Medicine, \\ Nashville, Tennessee, USA
}

\begin{abstract}
Summary
A toxin isolated from Group B $\beta$-hemolytic streptococci, Type III was infused into adult sheep and newborn lambs. A twophased reaction was observed. There was an initial phase of pulmonary hypertension and high flow of protein-poor lymph. This was followed by a second phase when pressures returned to baseline but lymph flow remained twice the baseline values and protein concentration in lymph increased. During the second phase there was a significant increase in lymph protein clearance, suggestive of increased microvascular permeability to protein. The absolute granulocyte count decreased to $10 \%$ of baseline values by $60 \mathrm{~min}$ after the infusion, and was followed by a variable return to baseline. The sheep with the largest changes in protein clearance were those who had the slowest return to baseline values. Pathologic examination of lung tissue revealed there was capillary dilation, interstitial edema, and large numbers of granulocytes in the lungs. The basement membranes of both capillaries and arterioles showed disruption and widening, along with fragmentation of the internal elastic membrane. This study provides morphologic and physiologic evidence of increased pulmonary vascular permeability after injection of streptococcal toxin associated with granulocyte trapping in the lung. We postulate that granulocytes may be involved as mediators of the pulmonary vascular injury.
\end{abstract}

Early onset Group B streptococcal disease in newborn infants has become a major cause of neonatal infectious mortality in the United States (16). Over $90 \%$ of symptomatic infants present with respiratory distress, usually out of proportion to the radiologic findings. Their course is characterized by progressive respiratory failure, evidence of pulmonary hypertension, and cardiovascular collapse. The reported mortality rate in some series is over $50 \%$ (15). Decreased numbers of circulating granulocytes are almost always present (18) and depletion of granulocyte stores in bone marrow aspirates has been associated with a fatal outcome (4).

We have previously reported that a complex, high molecular weight toxin can be isolated from the culture media of Type III, Group B $\beta$-hemolytic streptococci (14). This toxin contains both protein and carbohydrate, but its toxicity is associated only with the carbohydrate portion. We have also shown that the carbohydrate portion is almost exclusively composed of mannose and that when infused into sheep it produces pulmonary hypertension and increased pulmonary vascular permeability (21). The similarity of these changes to those seen in newborn infants with Group B streptococcal sepsis warrants further study of this animal model, which may provide a means to study the mecha- nisms involved in the pathophysiology of this devastating disease.

The purpose of this investigation was an attempt to quantitate the hemodynamic effects of this toxin, to determine the possible role of white blood cells as mediators and to determine the ultrastructural changes that characterize the tissue response to the presence of toxemia with Type III Group B streptococcal polysaccharide.

\section{MATERIALS AND METHODS}

Adult sheep. Seven yearling sheep $(35-45 \mathrm{~kg}$ ) were prepared for chronic lung-lymph collection as described previously (8). Through bilateral thoracotomies, catheters were placed directly into the main pulmonary artery, left atrium and the efferent duct from the caudal mediastinal lymph node. The tail of the node was resected to eliminate non-pulmonary lymph and catheters placed in the right atrium and thoracic aorta through neck vessels. Lymph collected from animals prepared in this way is primarily from the lung because lymph flow increases when pulmonary vascular pressure is increased mechanically, but lymph flow does not increase when systemic venous pressure is increased.

All experiments were done with the sheep unanesthetized, standing unrestrained in a cage. Vascular pressures were measured continuously with pressure transducers (Statham P23Gb, Gould-Statham Instruments, Inc., Hato Rey, PR) and an electronic recorder (Hewlett-Packard Co., Palo Alto, CA). Lymph flow was measured at 15 -min intervals by recording the volume drained into a graduated tube. Total protein concentration was measured in plasma from blood drawn each hour and in lymph pooled at 30 -min intervals, using an automated system (AutoAnalyzer, Technicon Instrument Corp., Tarrytown, NY) by a modified Biuret method (9).

Polyacrylamide gradient gel electrophonesis was used to separate proteins in lymph and blood plasma samples from baseline and phase II periods as described previously (1). Briefly, 4-30\% polyacrylamide gradient gels (Pharmacia Fine Chemicals, Piscataway, NJ) were used and eight protein fractions were consistently identified. To estimate the effective molecular radius of each fraction, the gels were calibrated with five proteins with known free diffusion coefficients. The radius of the eight plasma and lymph fractions was estimated from a standard curve of migration distance plotted against Einstein-Stokes radius for the five known proteins. Lung-lymph protein clearance was calculated with the formula: $\mathrm{Cl}=\mathrm{LQ}(\mathrm{L} / \mathrm{P})$, where $\mathrm{LQ}$ is lymph flow and $\mathrm{L} / \mathrm{P}$ is the lymph/plasma total protein concentration ratio.

Blood for white cell studies was drawn from the aortic catheter. Samples were obtained twice during the baseline period and then 
at $30,60,180$, and $300 \mathrm{~min}$ after the infusion of toxin. Total leukocyte counts were performed electronically in a model ZBI Coulter Counter (Coulter Electronics, Hileah, FL), specifically adjusted for counting sheep leukocytes. Blood smears were stained with Wright's stain and subjected to a 200 cell differential count. Total granulocyte count was calculated by multiplying the total leucocyte count by the percentage of granulocytes.

A mature granulocyte was defined as a neutrophil in which the lobes were connected by a thread or filament. Cells in which the nucleus was folded or in which possible segmentation was otherwise observed were counted as mature cells. All other forms were considered immature. A proportion expressing the fraction of immature to total granulocytes was calculated for the baseline period, 20, and $300 \mathrm{~min}$ after the infusion. At 60 and $180 \mathrm{~min}$ there were insufficient neutrophilic forms to provide an adequate count.

Newborn lambs. Five lambs ranging from 3-6 days of age were used for these experiments. Under local anesthesia catheters were placed through a cutdown directly in the tarsal vein and carotid artery and a \#5 French Swan-Ganz catheter was placed in the pulmonary artery through the jugular vein. Vascular pressures were monitored continuously and recorded at consecutive 15 . minute intervals. After at least $2 \mathrm{~h}$ of stable baseline readings, streptococcal toxin was infused intravenously. At about $3 \mathrm{~h}$ after the infusion, a bolus of $\left[{ }^{51} \mathrm{Cr}\right]$ erythrocytes was injected to label the blood. The lambs were anesthetized with penthotal $(25 \mathrm{mg} /$ $\mathrm{kg}$ IV), the lungs excised, and a sample of blood drawn from the heart. Extravascular lung water and dry weight of bloodless lung were then calculated by the method of Pearce et al. (20), which includes a correction for pulmonary blood using the $\left[{ }^{51} \mathrm{Cr}\right]$ erythrocytes. Lung tissue was taken from upper and lower lobes for examination by light and transmission electron microscopy. Tissues were processed as previously described (24).

The isolation of the toxic polysaccharide has been previously described (14). The dose used in all infusions was $2.0 \mathrm{mg}$ suspended in $80 \mathrm{ml}$ of $0.9 \% \mathrm{NaCl}$ solution for the adult sheep and $750 \mathrm{mcg}$ in $10 \mathrm{ml}$ of $0.9 \% \mathrm{NaCl}$ for the lambs.

All statistical calculations were done using a two-tailed paired $t$ test and the least squares method for regression lines. A $P$ value of less than 0.05 was considered significant.

\section{RESULTS}

Adult sheep. Nine infusions of the toxin were done. The response was biphasic as described previously (21). There was an initial phase of pulmonary hypertension and high flow of proteinpoor lymph followed by a second phase when pulmonary artery pressure was slightly above baseline and stable, lymph flow was twice the baseline value and the ratio of protein concentration in lymph to that in plasma increased. The data is summarized in Table 1 . The values for phase $\mathrm{I}$, because it is a transient phase, are obtained at the peak of the pulmonary artery pressure. All phase II values are the average of at least $3 \mathrm{~h}$ of steady state. Systemic blood pressure, not shown in the Table, showed no significant changes during the course of the experiment. During the second phase, lung lymph flow was two times higher than baseline, and the lymph to plasma protein concentration ratio had returned to near baseline, resulting in a significant increase in lymph protein clearance.

Figure 1 shows the relationship between lung-lymph protein clearance and molecular size for the eight protein fractions. There is a decline in protein clearance with increasing molecular radius during the baseline period that remains unchanged during the second phase when total protein clearance is increased and resulting in a relatively larger increase in lymph clearance for the large proteins.

The baseline white blood cell values for all sheep were within the normal range for sheep as described by Schalm (23). The total white blood cell count dropped within the first hour after the infusion of the polysaccharide to $30 \%$ of baseline values. As shown in Figure 2, this leukopenia was due primarily to a decrease in granulocytes. The absolute granulocyte count fell to $10 \%$ of baseline values by $60 \mathrm{~min}$ followed by a recovery phase that was variable. In two instances the granulocyte counts were higher than baseline by $5 \mathrm{~h}$, two had returned to baseline values, and five remained below. The ratio between immature and total granulocytes increased significantly from $0.023 \pm 0.01$ and 0.026 \pm 0.01 during baseline and $30 \mathrm{~min}$ to $0.153 \pm 0.03$ at $5 \mathrm{~h}(P<$ $0.05)$.

The pulmonary changes were analyzed as a function of the decrease in circulating granulocytes for the five sheep in which lymphatic canulation was successful. Even though low granulocyte counts were seen in all sheep by $60 \mathrm{~min}$, there was large variability during the second phase (Fig. 2). Those sheep with

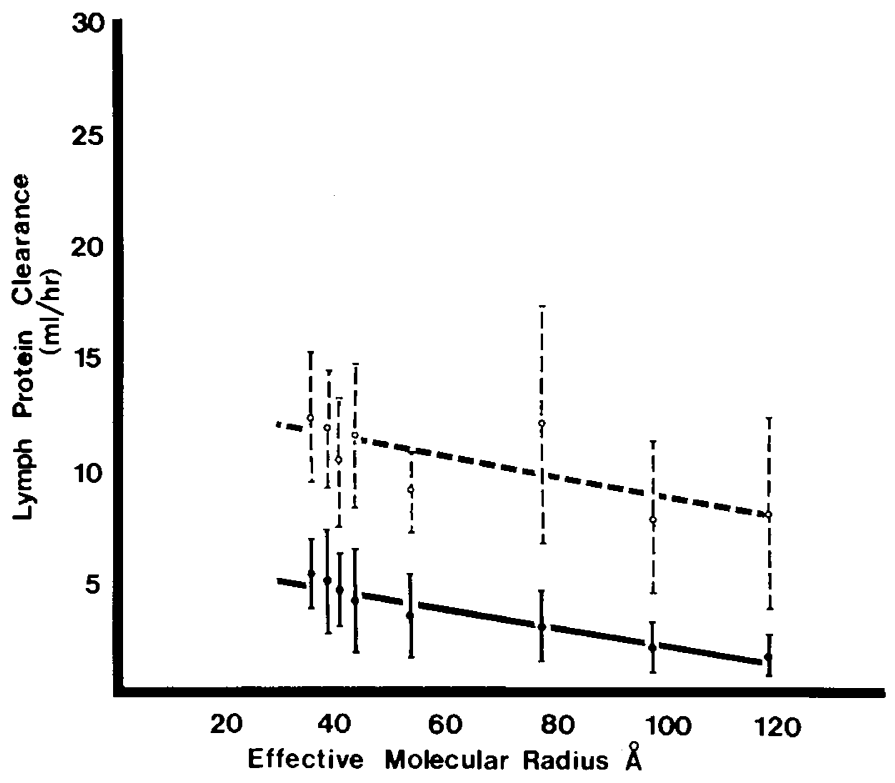

Fig. 1. Steady-state lung lymph clearance of eight protein fractions as a function of molecular radius during baseline $(-)$ and toxin infusion during the second phase $(---)$. Bars represent mean \pm S.D. Both slopes are significantly different from zero $(P<0.05)$ but not different from each other. Lymph protein clearance during phase II for each protein size was significantly different from baseline $(P<0.05)$.

Table 1. Adult sheep, values given as mean \pm S.E.M.

\begin{tabular}{|c|c|c|c|c|c|}
\hline & \multicolumn{2}{|c|}{ Mean pressures $(n=9)$} & \multicolumn{3}{|c|}{ Lymph data $(n=5)$} \\
\hline & $\begin{array}{c}\text { Pulmonary artery } \\
(\mathrm{mmHg})\end{array}$ & Left atrium $(\mathrm{mmHg})$ & Lymph flow $(\mathrm{ml} / \mathrm{h})$ & $\begin{array}{c}\text { Protein concentration ra- } \\
\text { tio (lymph/plasma) }\end{array}$ & $\begin{array}{c}\text { Lymph protein clear- } \\
\text { ance }(\mathrm{ml}) \\
\end{array}$ \\
\hline Baseline & $15 \pm 0.8$ & $3.9 \pm 0.7$ & $7.8 \pm 2.4$ & $0.66 \pm 0.01$ & $5.2 \pm 1.6$ \\
\hline Phase I & $42 \pm 4.5^{\prime}$ & $-1.5 \pm 1.8$ & $26 \pm 3.0^{1}$ & $0.48 \pm 0.05^{1}$ & \\
\hline Phase II & $20 \pm 1.9$ & $2.7 \pm 0.8$ & $17 \pm 3.0^{1}$ & $0.62 \pm 0.03$ & $10.4 \pm 1.7^{1}$ \\
\hline
\end{tabular}

\footnotetext{
${ }^{1} P<0.05$.
} 


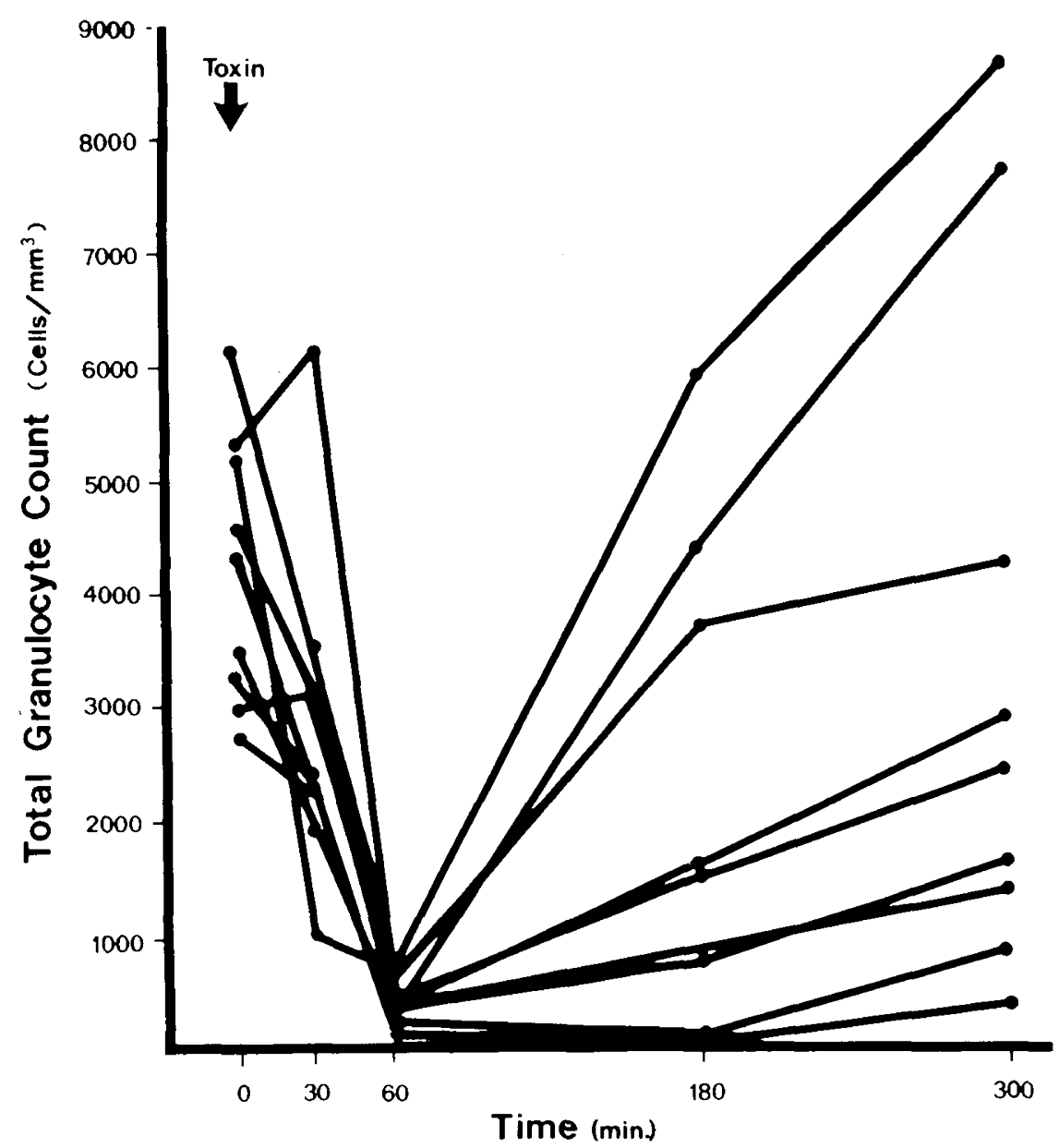

Fig. 2. Total granulocyte counts as a function of time for the nine toxin infusions. Two milligrams of toxin were infused at time zero.

the largest changes in protein clearance were those who had the slowest recovery. This is illustrated in Figure 3.

Newborn lambs. The newborn lambs behaved identically as the adult animals. Pulmonary artery pressure significantly increased during the first phase from $22 \pm 2.8$ to $39 \pm 6 \mathrm{~mm} \mathrm{Hg}$ $(P<0.05)$. Pulmonary artery wedge pressure increased during

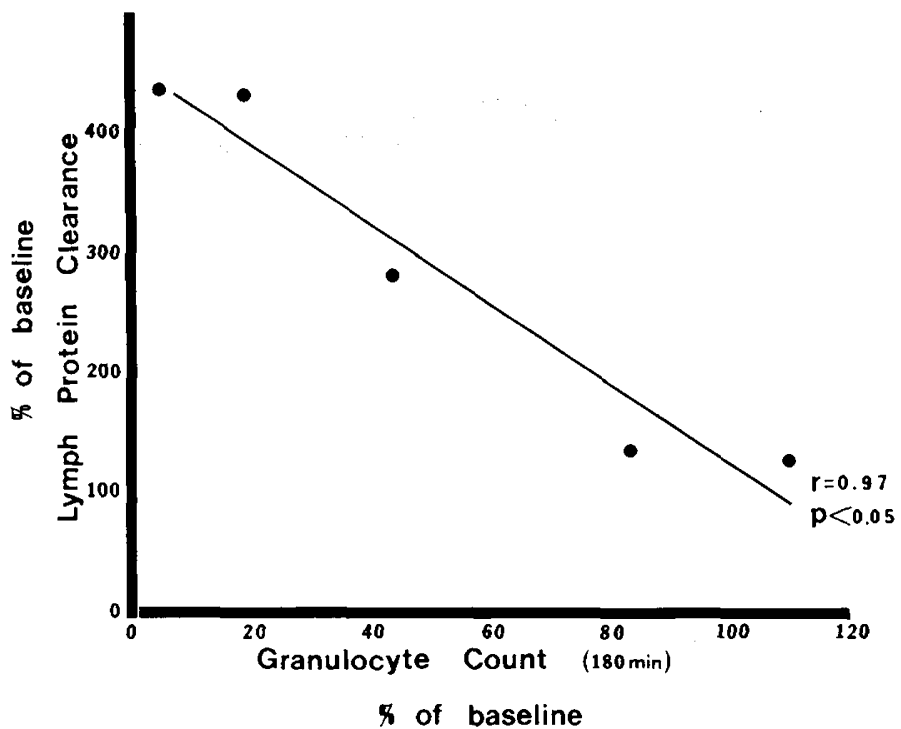

Fig. 3. Relationship between average lymph protein clearance and granulocyte count at $180 \mathrm{~min}$ after the infusion of toxin. Each dot represents one sheep. the initial phase from $5.5 \pm 0.04$ to $7.8 \pm 1 \mathrm{mmHg}$ and remained somewhat elevated during the second phase $(7.0 \pm 0.5 \mathrm{mmHg})$. No significant changes were seen in systemic blood pressure. Extravascular lung water per gram of bloodless lung was not significantly increased when compared with published values for normal 5-day-old lambs (2).

All five lambs showed remarkably similar pathology, differences being largely a matter of degree. Grossly, the lungs of all animals showed patchy aeration. They were pink and no edema fluid was present in large airways. On light microscopy, there was patchy loss of alveolar volume alternating with overdistention of neighboring alveoli. In several instances, subpleural hemorrhage was evident, extending into the septae. Lymphatic dilatation was not prominent, but there was perivascular cuffing of small arterioles. Alveolar duct and respiratory bronchiolar epithelium was intact with no sloughing evident. In some lambs small arterioles were constricted and in others, dilated. Capillaries and venules were uniformly dilated, and granulocytes were readily seen in capillaries and small arterioles. In several lambs, granulocytes were also seen in scattered small conducting airways. Protein-containing edema fluid was also present in these same areas. When examined with Masson's stain, the internal elastic membrane of some of the small arterioles was fragmented.

Transmission electron microscopy confirmed the findings seen by light microscopy and provided additional detail. The most prominent lesions were in the vasculature. There was marked capillary dilatation, and many capillaries were filled with granulocytes (Fig. 4). Some of these were undergoing dissolution of their limiting membrane and free granules and cell debris were frequently seen. Occasional granulocytes were seen in the interstitial spaces around small arterioles and in a few instances they were in the protein-rich, fluid-filled airspaces. The endothelial 


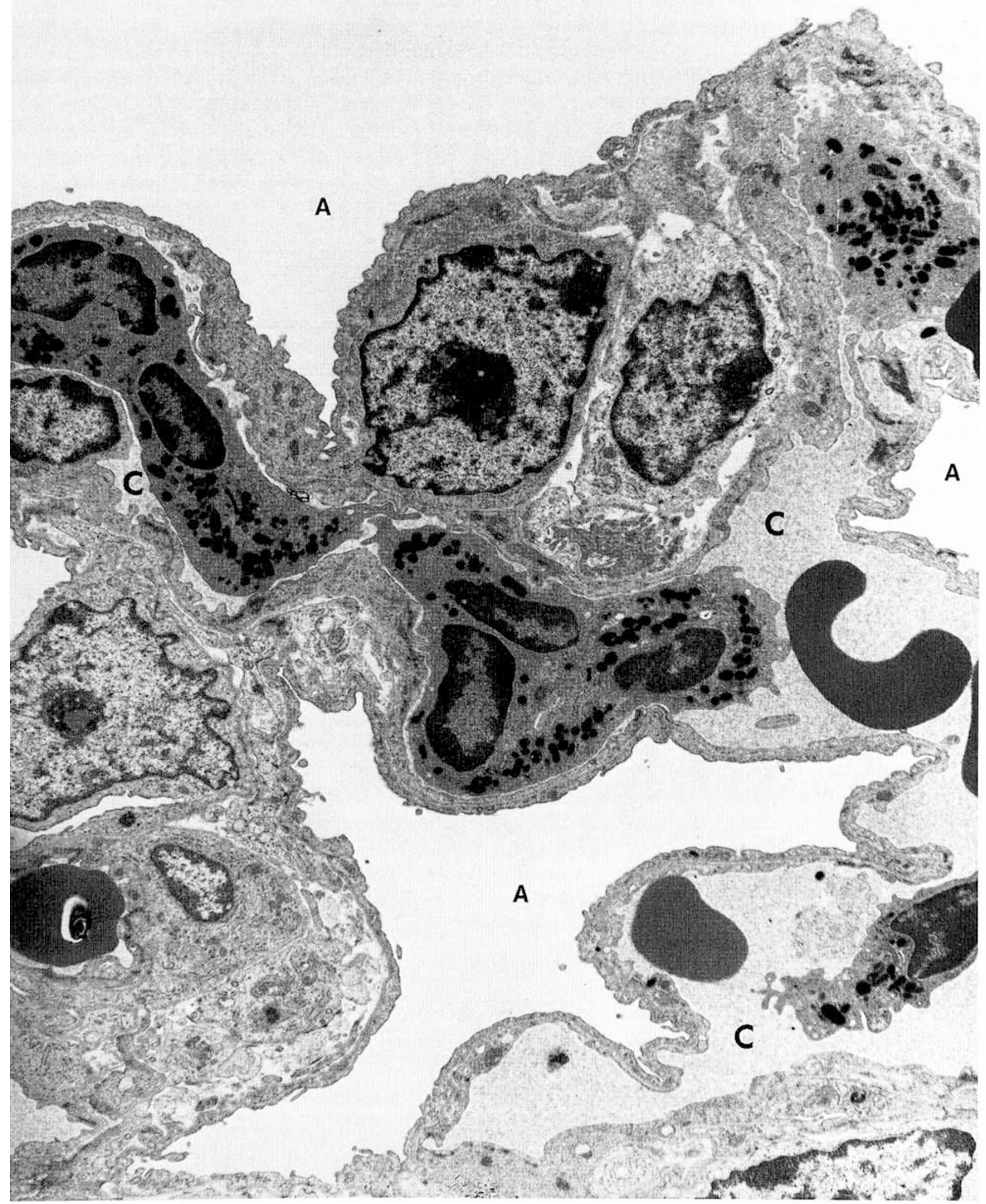

Fig. 4. Electron micrograph of interalveolar septa from the lung of a 4-day-old lamb which had been injected with streptococcal toxin $4 \mathrm{~h}$ before necropsy. There is marked capillary dilatation with polymorphonuclear leukocytes filling the lumina of several segments. $(A)$ alveolus and $(C)$ capillary; uranyl acetate and lead citrate, magnification $\times 8000$.

cells of capillaries showed remarkably active pinocytosis, and pinocytotic vesicles were also seen in overlying type I epithelium. The basement membrane beneath capillary endothelium frequently appeared to be fragmented, but tight junctions appeared intact. Type I epithelial basement membrane was unaffected in most areas, but where edema fluid appeared in airspaces, it appeared fragmented.

The endothelium of small arterioles showed active pinocytosis and the basement membranes were widened, ill defined, and, occasionally, disrupted. Fibers of the internal elastic membrane 
appeared grossly fragmented (Fig. 5). Basement membranes around smooth muscle cells were intact, but there was remarkable interstitial edema fluid containing much protein (Fig. 6) and an occasional granulocyte. Collagen bundles appeared unaffected.

Bronchiolar epithelial cells showed intact basement membranes and tight junctions, but mitochondrial membranes were disrupted in some. Many cells appeared swollen, and some contained lipid droplets. Type II epithelial cells uniformly showed vacuolated lamellar bodies with occasional electron dense remnants clinging to the lamellar membranes.

\section{DISCUSSION}

Group B streptococcal septicemia in newborn infants is manifested by respiratory failure, leukopenia, and shock $(15,16)$. The degree of leukopenia has been cited previously as a prognostic factor (4) and it correlates with the severity of the respiratory symptoms and the presence of cardiovascular collapse. We have previously described that a polysaccharide isolated from Type III group B streptococcus produces pulmonary hypertension and increased pulmonary vascular permeability in sheep. In the present study we attempted to further characterize the response to this polysaccharide to confirm the ability of this model to reproduce the pathophysiologic changes seen in newborn infants and to investigate the possible role of white blood cells in the pathogenesis of the pulmonary vascular injury.

When the sheep were infused with the polysaccaride there was a transient phase of pulmonary hypertension followed by a prolonged phase when pulmonary pressures returned to near baseline and lymph-protein clearance increased out of proportion to the change in vascular pressures. This suggests that permea- bility of the microvascular wall to protein was increased during this phase of the reaction (21). Concurrently there was a dramatic reduction in the number of circulating granulocytes and an increase in the ratio of immature to total granulocytes, suggesting that the observed neutropenia was the result of extensive margination of granulocytes. The large number of granulocytes seen in the lungs of the newborn lambs sacrificed during the second phase suggests that the major site of granulocyte trapping is the pulmonary capillary bed. The correlation between the degree of granulocytopenia and the increase in protein clearance suggests that the granulocyte may play an important role in the genesis of the pulmonary vascular injury.

Even though lymphatic canulation was not done in the newborn lambs the pathologic changes are consistent with the findings in the adult sheep. At the dosage used and with a single bolus infusion, no changes were seen in systemic arterial pressure in either the adult sheep or the newborn lambs, whether or not a higher dosage or a continuous infusion will result in systemic arterial changes has not been investigated.

Granulocyte depletion has been shown to prevent the pulmonary vascular changes due to endotoxemia (13) or microembolization (11). Granulocytes are capable of the production of oxygen radicals, lysosomal enzymes, and arachidonate products that have been shown to injure vascular endothelium $(5,12,22)$. The most striking pathologic findings in the lungs of lambs sacrificed during the phase of increased vascular permeability after intravenous toxin infusion were in the basement membranes of both capillaries and arterioles. Here, disruption and widening of the basement membranes occurred along with fragmentation of the internal elastic membranes of arterioles. These changes were associated with leukostasis in capillaries and with degranulation and disruption of the plasma membranes of gran-

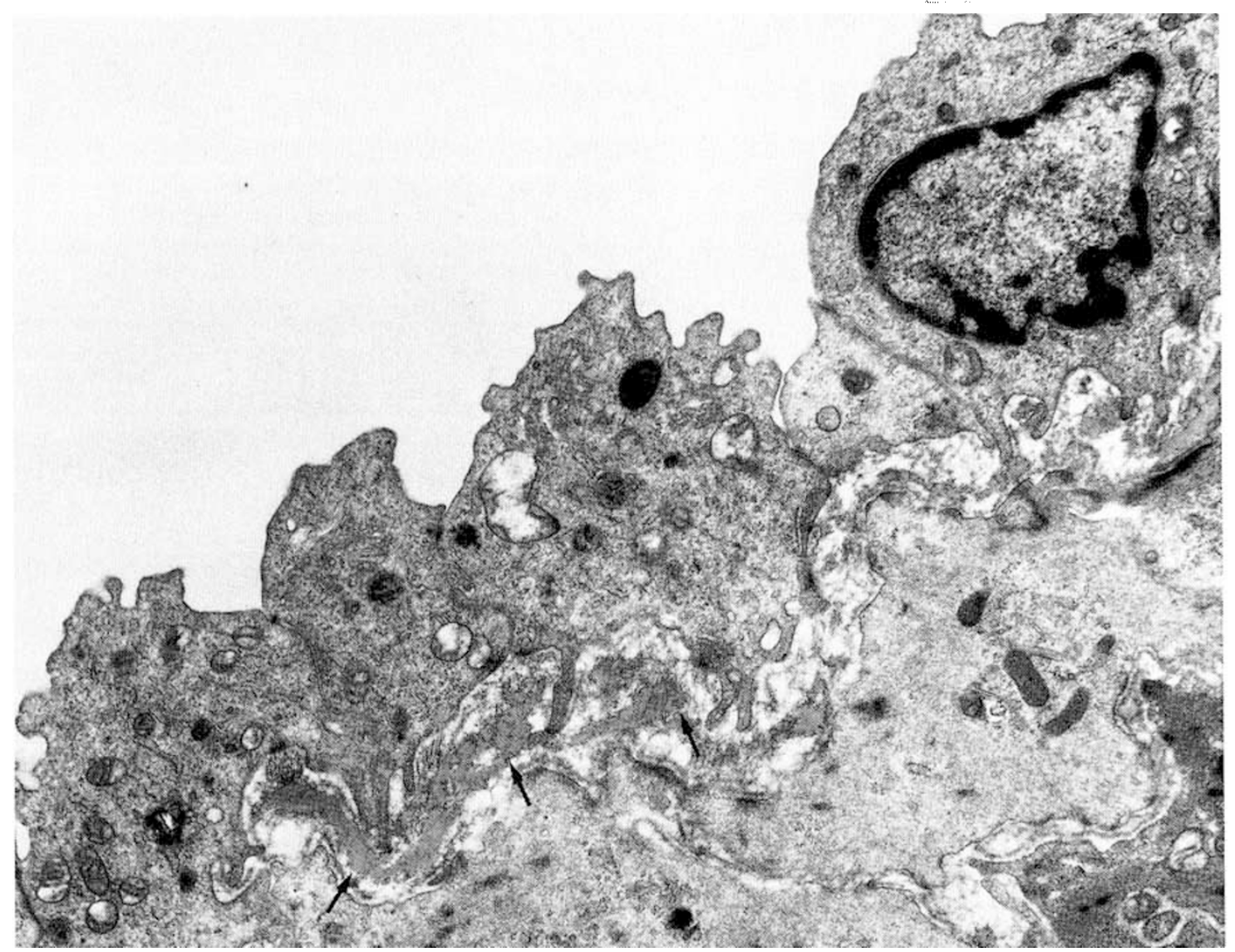

Fig. 5. Electron micrograph of the intima of a small muscular segment of the pulmonary artery from the lung of a 6-day-old lamb which had been injected with streptococcal toxin $18 \mathrm{~h}$ before necropsy. There is subendothelial edema, disruption of the endothelial basement membrane and the internal elastic membrane (arrows); uranyl acetate and lead citrate, magnification $\times 14000$. 


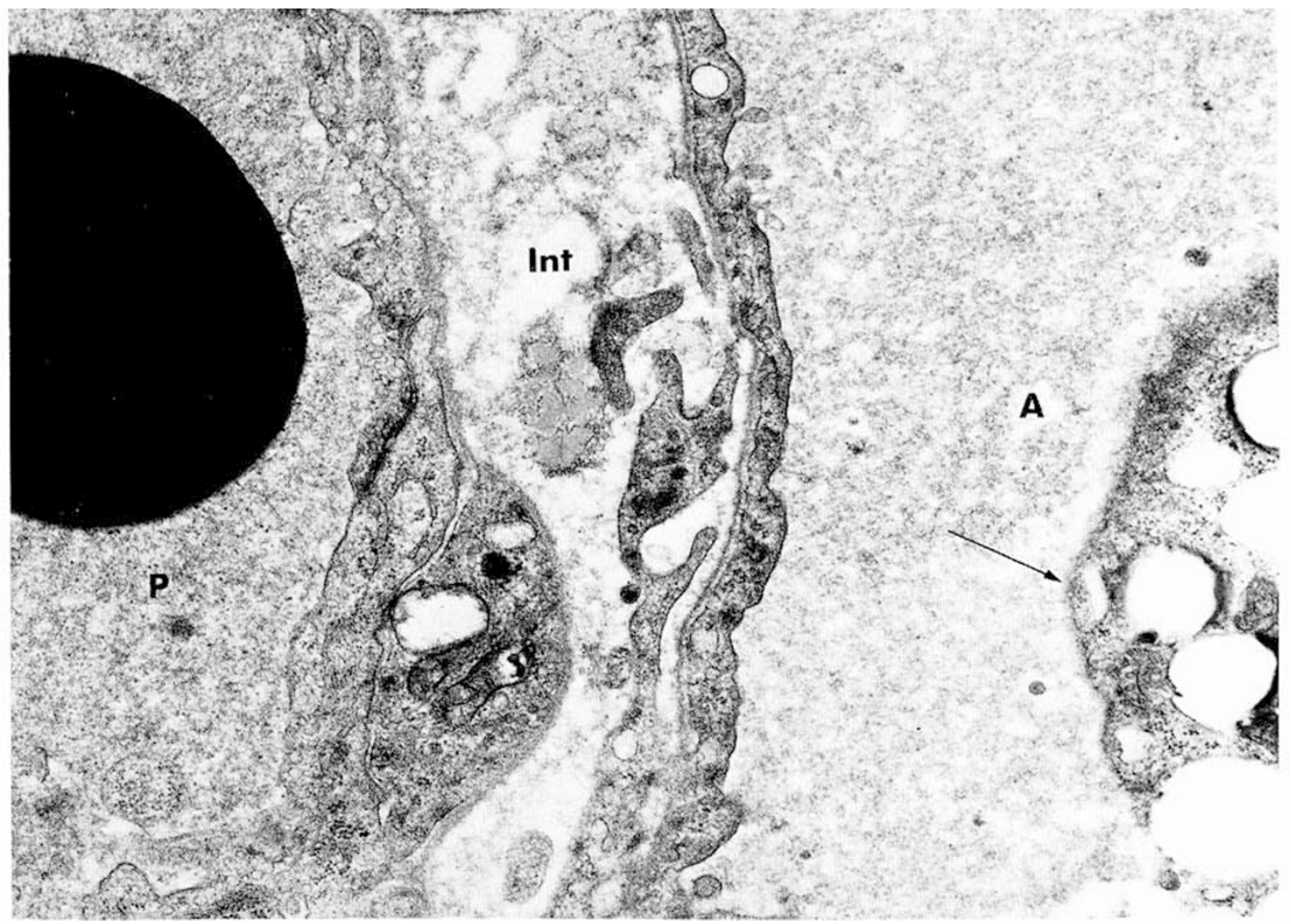

Fig. 6. Electron micrograph of a portion of an intraalveolar septum from the lung of a 6-day-old lamb which had been injected with streptococcal toxin $18 \mathrm{~h}$ before necropsy. Interstitial edema fluid has separated the epithelial and endothelial basement membranes. A protein rich fluid which is as electron opaque as plasma $(P)$ fills the airway $(A)$. The apex of a type II cell (arrow) contains vacuolated lamellar bodies; Int, interstitial space; uranyl acetate and lead citrate, magnification $\times 20250$.

ulocytes. Marked interstitial edema containing protein, and, in some instances, protein-rich fluid containing cell debris in airways, were also related findings. The changes seen in the integrity of the endothelial basement membrane and internal elastic membrane may explain the increase in permeability to protein as well as the change in the sieving properties of the endothelium suggested by the relatively larger increase in lymph clearance for the larger proteins. These changes may be due to substances produced by granulocytes.

Pulmonary leukostasis and leukopenia are also known to occur during adult respiratory distress syndrome (17), hemodialysis (7), and cardiopulmonary bypass (3). Complement activation is assumed to be the cause because the same changes develop in several animal species shortly after the infusion of autologous plasma that has been exposed to complement activating agents, including polysaccharides such as inulin, zymosan or polycellulose membranes of hemodialysis coils (6). Complement activation through the alternative pathway, characteristic of gram negative endotoxin shock (19), has also been shown to occur in infants with early onset group B streptococcal disease (10). It is tempting to postulate a similar mechanism in the development of leukopenia in these infants. This cannot be assesed with the data now available.

The present study provides morphologic and physiologic evidence that Type III Group B $\beta$-hemolytic streptococc $i$ are capable of producing a polysaccharide that, at least in sheep, reproduces the pathophysiologic changes seen in human infants with early onset disease and suggests that granulocytes may be involved as mediators of the pulmonary vascular injury.

\section{REFERENCES AND NOTES}

1. Brigham K. L. and Owen P. J.: Mechanism of the serotonin effect on lung transvascular fluid and protein movement in awake sheep. Circ. Res., 36 : $76 !(1975)$
2. Brigham K. L., Sundell H., Harris T. R., Catterton Z., Kovar I., and Stahlman M. T.: Lung water and vascular permeability in sheep. Newborns compared with adults. Circ. Res., 42: 851 (1978).

3. Chinoweth D. E Cooper S. W. Hugli T. E Stewart R. W. Blackstone E. H. and Kirklin J. W.: Complement activation during cardiopulmonary bypass. Evidence for generation of $\mathrm{C}_{3}$ a and $\mathrm{C}_{5}$ a anaphylatoxins. N. Engl. J. Med., 304: 497 (1981).

4. Christensen R. D. and Rothstein G.: Exhaustion of mature marrow neutrophils in neonates with sepsis. J. Pediatr., 96: 316 (1980).

5. Cochrane C. G. and Aikin B. S.: Polymorphonuclear leukocytes in immunologic reactions. The destruction of vascular basement membrane in vivo and in vitro. J. Exp. Med., 124: 733 (1966).

6. Craddock P. R., Fehr J., Brigham K. L., Kronenberg R. S., and Jacob H. S.: Complement and leukocyte-mediated pulmonary dysfunction in hemodyalisis. N. Engl. J. Med. 296: 769 (1977).

7. Craddock P. R., Fehr J., Dalmasso A. P., Brigham K. L., and Jacob H. S.: Hemodyalisis leukopenia. Pulmonary vascular leukostasis resulting from complement activation by dialyzer cellophane membranes. J. Clin. Invest. 59: 879 (1977).

8. Erdman A. J. III. Vaughan T. R., Brigham K. L., Woolverton W. C.. and Staub N. C.: Effect of increased vascular pressure on lung fluid balance in unanesthetized sheep. Circ. Res., 37: 271 (1975).

9. Failing J., Buckley M., and Zak D.: Automatic determination of serum proteins. Am. J. Clin. Pathol., 33: 83 (1960).

10. Fenton L. J. and Strunk R. C.: Complement activation and group B streptococcal infection in the newborn: Similarities to endotoxin shock. Pediatrics, 60: 901 (1977).

11. Flick M. R. Perel A, and Staub N. C.: Leukocytes are required for increased lung microvascular permeability after microembolization in sheep. Circ. Res., 48: 344 (1981).

12. Goetzel E. J.: Mediators of immediate hypersensitivity derived from arachidonic acid. N. Engl. J. Med., 303: 822 (1980).

13. Heflin A. C., Jr. and Brigham K. L.: Prevention by granulocyte depletion of increased vascular permeability of sheep lung following endotoxemia. J. Clin. Invest. 68: 1253 (1981).

14. Hellerqvist C. G., Rojas J., Green R. S., Sell S., Sundeil H., and Stahiman M. T.: Studies on group B $\beta$-hemolytic streptococcus. I. Isolation and partial characterization of an extracellular toxin. Pediatr. Res., 15:892 (1981)

15. Horn. K. A., Meyer W. T., Wynick B. C., and Zimmerman R. A.: Group B streptococcal neonatal infection. J. Am. Med. Assoc., 230: 1165 (1974).

16. Howard. G. B. and McCraken, G. H., Jr.: The spectrum of group B streptococcal infection in infancy Am. Dis Child 128.815 (1974). 
17. Jacob H. S., Craddock P. R., Hammerschmidt D. E., and Moldow C. F.: Complement-induced granulocyte aggregation. An unsuspected mechanism of disease. N. Engl. J. Med., 302: 789 (1980).

18. Manroe B. L.. Rosenfeld C. R.. Weinberg A. G., and Browne R.: The differential leukocyte count in the assesment and outcome of early-onset neonatal group B streptococcal disease. J. Pediatr. 91:632 (1977).

19. McCabe W. R.: Serum complement levels in bacteremia due to gram-negative organisms. N. Engl. J. Med., 288: 21 (1973).

20. Pearce M. L.. Yamashita J., and Beazell J.: Measurement of pulmonary edema. Circ. Res.. 16: 482 (1965).

21. Rojas J., Green R. S., Hellerqvist C. G., Olegard R., Brigham K. L.. and Stahlman M. T.: Studies on group B $\beta$-hemolytic streptococcus. Il. Effects on pulmonary hemodynamics and vascular permeability in unanesthetized sheep. Pediatr. Res.. 15: 899 (1981).

22. Sacks T., Moldow C. F., Craddock P. R., Bowers T. K., and Jacob H. S.: Oxygen radicals mediate endothelial cell damage by complement-stimulated granulocytes. An in vitro model of immune vascular damage. J. Clin. Invest.. 61: $1161(1978)$
23. Schalm O. W., Editor: Veterinary Hematology, II Edition. pp. 237-246 (Lea and Febiger, Philadelphia, 1971).

24. Sundell H. W. Gray M. E. Relier J. P., Kovar I. Z., Catterton W. Z.. Swift L. L., and Stahlman M. T.: The effects of ACTH on lung maturation in fetal lambs. AM. J. Pathol.. 97: 393 (1979).

25. This work was done during Dr. Brigham's tenure as an Established Investigator of the American Heart Association

26. We are indebted to Gerda Resch, Patricia Minton, Rao Gaddipati. Fred Morris. Mary Dickie and Nancy Embry for their expert technical assistance and to Diane Peevler for secretarial assistance in the preparation of the manuscript. 27. Fellow supported by the Tennessee Lung Association.

28. Requests for reprints should be addressed to: Dr. Jorge Rojas, Baptist Hospital, 2000 Church Street. Nashville. Tennessee 37236.

29. This research was supported by a grant from the National Institutes of Health HL 22520

30. Received for publication September 3, 1982.

31. Accepted for publication May 20, 1983.

\title{
Interaction between Bovine Casein and $V$. Cholerae Enterotoxin in the Rabbit Ileal Loop
}

\author{
DAVID A. CLARK, ${ }^{(23)}$ RONALD P. PELLEY, AND ALBERT J. SCHNEIDER
}

Division of Neonatology, Department of Pediatrics and Division of Geographic Medicine, Department of Medicine, Case Western Reserve University and University Hospitals, Cleveland, Ohio and Department of Pediatrics, SUNY, Upstate Medical Center, Syracuse, New York, USA

\section{Summary}

Secretory IgA from human breast milk neutralizes cholera enterotoxin in the rabbit ileal loop system. No similar protection by purified bovine milk proteins could be demonstrated; however, one bovine milk protein, casein, had a deleterious effect on intestine exposed to very small quantities of enterotoxin. Highly purified cholera toxin (10 or $100 \mathrm{ng}$ ) was incubated with bovine protein solutions for $60 \mathrm{~min}$ at $37^{\circ} \mathrm{C}$. One-milliliter aliquots were then injected into prepared rabbit intestine loops. The animals were sacrificed at $18 \mathrm{~h}$ and the intestinal loop contents were aspirated, and a volume to length of loop ratio $(\mathrm{V} / \mathrm{L})$ was determined. The activity of $100 \mathrm{ng}$ of toxin was not enhanced by the majority of bovine milk proteins, but bovine casein caused a 14 $40 \%$ increase in the fluid production $(\mathrm{V} / \mathrm{L}$ of casein + toxin versus toxin, 1.05 versus 0.92 and 1.82 versus 1.30 ). All of the bovine proteins but casein inhibited the action of low dose enterotoxin. Bovine casein caused a $78-90 \%$ increase in fluid production by loops exposed to a suboptimal toxin dose $(10 \mathrm{ng})(\mathrm{V} / \mathrm{L}$ of casein + toxin versus toxin, 1.12 versus 0.63 and 0.95 versus $0.50)$. Virtually all of this enhancement of enterotoxin fluid response resided in the purified alpha-casein fraction.

\section{Abbreviation}

$\mathrm{V} / \mathrm{L}$, volume to length of loop ratio

Numerous gram-negative bacteria cause diarrhea by producing an enterotoxin that induces fluid loss into the intestine. Vibrio cholerae is the prototype for enterotoxin-induced disease, but milder forms can be induced by a wide variety of coliforms, including $E$. coli and Klebsiella sp. $(9,11,12)$. Although toxigenic
$E$. coli diarrhea is seldom fatal in adults, its effect on the neonate can be devastating. $(2,14,20)$. Clinically, the effects of these bacterial intoxications can be either ameliorated or exacerbated by multiple factors, one of which is secretory IgA directed against enterotoxin (19). These protective factors in breast milk may confer resistance to diarrhea in infants receiving mother's milk in underdeveloped countries (8).

While studying this protective effect of breast milk, we examined other milk proteins for their effect on enterotoxin-induced diarrhea. A number of bovine proteins were examined, and no additional factors were found that were specifically protective. We found that there is one milk protein, alpha-casein, present in large amounts in cow's milk that has a deleterious effect on intestine exposed to very small quantities of enterotoxin.

\section{MATERIALS AND METHODS}

Proteins. Highly purified Vibrio cholerae enterotoxin (Schwarz Mann, Orangeburg, NY, Lot BZ 2487) was initially suspended at a concentration of $10 \mu \mathrm{g} / \mathrm{ml}$ in phosphate buffered saline and stored at $4^{\circ} \mathrm{C}$. Before use, it was diluted in phosphate buffered saline to a concentration of either $10 \mathrm{ng}$ or $100 \mathrm{ng} / \mathrm{ml}$. Bovine casein hydrolysate (Sigma, St. Louis, MO, Lot 59B21000), bovine casein (Pentex, Kankakee, IL, Lot 96-005-1), bovine Beta lactoglobulin A (Pentex, Lot 96-003), bovine Beta lactoglobulin B (Pentex, Lot 96-004), bovine lactalbumin (Nutritional Biochemicals, Chagrin Falls, $\mathrm{OH}$ ), and bovine gamma globulin (Schwarz Mann, Lot Y3145) were dissolved in phosphate buffered saline at a concentration of $10 \mathrm{mg} / \mathrm{ml}$ just before use.

Isolation of human casein. One liter of pooled human breast milk was collected via breast pump from 15 normal nursing mothers at University Hospitals, Cleveland, $\mathrm{OH}$. The milk was 